\title{
Novos Rumos do Direito e Desenvolvimento
}

\author{
Lucas do Monte Silva \\ Acadêmico do curso de Direito da Universidade Federal do \\ Rio Grande do Norte (UFRN). Bolsista do Conselho Nacio- \\ nal de Desenvolvimento Científico e Tecnológico, na base \\ da pesquisa "Direito e Desenvolvimento" da mesma uni- \\ versidade. Membro da Equipe Editorial da Revista Direito \\ e Liberdade, publicada pela Escola da Magistratura do Rio \\ Grande do Norte (Esmarn). lucasdomonte1@gmail.com
}

\section{Patrícia Borba Vilar Guimarães}

Professora-adjunta da Universidade Federal do Rio Grande do Norte (UFRN). Doutora em Recursos Naturais pela UFCG. Líder da Base da Pesquisa "Direito e Desenvolvimento" da UFRN. patriciaborb@gmail.com

\begin{abstract}
Resumo
0 presente artigo se propõe a analisar os novos rumos aos quais o Direito e o Desenvolvimento (D\&D) se encaminham, traçando os caminhos que estão se tornando relevantes nessa discussão, bem como busca estabelecer as bases para uma nova perspectiva do desenvolvimento, em cujos pilares estejam a abertura, a pluralidade, o texto constitucional e a dignidade humana. Também procura oferecer, preliminarmente, proposições de mudanças para que as áreas em comento possuam uma maior eficácia no cotidiano dos cidadãos. Para tanto, utilizou-se da pesquisa bibliográfica e documental bem como do método hipotético-dedutivo, para delinear os novos rumos do Direito e Desenvolvimento, quais sejam: i) a efetivação dos direitos fundamentais como fundamento do desenvolvimento; ii) a colaboração público-privada como instrumento do desenvolvimento; iii) a relevância do pluralismo jurídico para a eficácia das normas jurídicas; iv) a utilização da propriedade intelectual como instrumento de fomento a inovação; v) a problemática da contextualização das bases teóricas ao local de instituição do processo de desenvolvimento.
\end{abstract}

Palavras-chave: Direito e desenvolvimento. Pluralismo jurídico. Efetivação dos direitos fundamentais. Colaboração público-privada. Contextualização de políticas. 


\title{
NEW TRENDS IN LAW AND DEVELOPMENT
}

\begin{abstract}
This article aims to analyze the new directions, to which the Law and Development, is headed by tracing the paths that are becoming relevant in this discussion, and seeks to establish the basis for a new vision of development, in whose pillars are the opening, plurality, constitutional text and human dignity. Also seeks to provide preliminarily change proposals for areas under discussion that have greater efficiency in everyday life of citizens. Therefore, we used the bibliographical and documentary research, as well as the hypothetical-deductive method, to outline the new directions of law and development, namely: i) the enforcement of fundamental rights as the foundation of development; ii) the public-private collaboration as an instrument of development; iii) the relevance of legal pluralism to the effectiveness of legal rules; iv) the use of intellectual property to promote innovation instrument; $v$ ) the issue of contextualization of the theoretical bases of the local implementation of the development process.
\end{abstract}

Keywords: Law and Development. Legal pluralism. Realization of fundamental rights. Public-private collaboration. Policy context.

\section{Sumário}

1 Introdução. 2 A Efetivação dos Direitos Fundamentais como Fundamento do Desenvolvimento. 3 A Colaboração Público-Privada como Instrumento do Desenvolvimento. 4 A Relevância do Pluralismo Jurídico para a Eficácia das Normas Jurídicas. 5 A Utilização da Propriedade Intelectual como Instrumento de Fomento à Inovação. 6 A Problemática da Contextualização das Bases Teóricas ao Local de Implementação do Processo de Desenvolvimento. 7 Conclusão. 8 Referências. 


\section{INTRODUÇÃO}

O desenvolvimento é fundamental para o futuro de uma nação e sua sociedade. Com isso em mente, o Direito, que é uma ciência que busca regular esse corpo social e sua qualidade de vida, por meio de uma abordagem emancipatória, vem nas últimas décadas aumentando a monta da categoria de estudo "Direito e Desenvolvimento".

O presente estudo busca investigar as veredas dessa categoria de estudo, analisando os rumos aos quais o Direito e o Desenvolvimento se encaminha, bem como busca estabelecer as bases para uma nova perspectiva do desenvolvimento, em cujos pilares estejam a abertura, a pluralidade, o texto constitucional e a dignidade humana. Para tanto, utilizou-se da pesquisa bibliográfica e documental bem como do método hipotético-dedutivo, para delineá-los.

Sendo assim, para facilitar a compreensão do tema dividiu-se a pesquisa em cinco momentos; cada um para discussão de um tema específico. Primeiro será discutida a efetivação dos direitos fundamentais, mostrando que estes possuem como núcleo central e irradiador o princípio da dignidade da pessoa humana, o qual foi erigido pela doutrina constitucionalista como o objetivo fundamental de toda e qualquer norma jurídica e sua efetivação, investigando sua importância para as novas concepções do desenvolvimento.

Em seguida põe-se em foco a colaboração público-privada como instrumento do desenvolvimento, albergando, nessa concepção, todo o todo tipo de sinergia entre os setores público e privado, que viabilize o fim precípuo de todo o dinamismo do desenvolvimento e o interesse público, abrangendo a dignidade humana e o bem-estar dos cidadãos. Nesse viés, demonstra-se que para se obter a eficiência e satisfação das necessidades do interesse coletivo, o Estado promove a abertura de competência das prestações, em princípio, suas ao setor privado. Dessa forma, as funções 
do Estado sofrem transformações. Suas atividades deixam de ser aquelas administrativo-burocráticas, hierárquicas, unitárias, para lograr a nova função de Estado fomentador-regulador-financiador-indutor.

Em um terceiro momento aborda-se a importância do pluralismo jurídico para o novo desenvolvimento e a inclusão de todos na sociedade. Assim, mostra-se que por o pluralismo jurídico em foco é fundamental diante da coexistência de ordenamentos vigentes na mesma sociedade, isto é, a existência de ordenamentos paralelos consegue abranger locais onde o ordenamento jurídico formal, tradicionalmente, não alcança. Nesse sentido, demonstra-se a importância de que os ordenamentos jurídicos, em geral, absorvam as regras não estatais, acolhendo-os e formalizando-os, no entanto sem descaracterizá-los, isto é, sem dificultar o acesso da população a tais mecanismos.

Após, põe-se em foco a utilização da propriedade intelectual como instrumento de fomento à inovação, mostrando que o aperfeiçoamento das normas e medidas referentes à proteção da propriedade intelectual dos inventores, investidores, estudantes e empresas, mostram-se essenciais para uma economia sólida, cujos ideais baseiam-se em ambiente profícuo para o desenvolvimento científico e uma mudança institucional e cultural (Querino e Silva, 2014).

Por fim, em um quinto momento, investiga-se a problemática da contextualização das bases teóricas ao local de efetivação do processo de desenvolvimento, mostrando que a contextualização às necessidades e particularidades da realidade e contexto local, na qual serão aplicadas as medidas de desenvolvimento, avulta importância nesse momento contemporâneo do D\&D. Assim, afastando e negando a fórmula única geral para todos os países - "one size fits all", é preconizada pelo teoria neoliberal do segundo momento, em prol de teorias e ideias que são formadas e cons- 
truídas de acordo com as especificidades de cada economia e região, por meio de análises empíricas e históricas do contexto onde as ideias serão aplicadas.

\section{A EFETIVAÇÃO DOS DIREITOS FUNDAMENTAIS COMO FUNDAMENTO DO DESENVOLVIMENTO}

A efetivação e concretização constitucional mostra-se fundamental para o processo de desenvolvimento nacional, em uma sociedade livre, justa e solidária, na qual se busca erradicar a pobreza, a marginalização e a discriminação, além reduzir as desigualdades sociais e regionais.

Nesse contexto, à luz constitucional, os direitos fundamentais possuem como núcleo central e irradiador o princípio da dignidade da pessoa humana, o qual foi erigido pela doutrina constitucionalista como o objetivo fundamental de toda e qualquer norma jurídica e sua efetivação. Consectariamente, há uma íntima relação entre a efetivação dos direitos fundamentais e a dignidade humana, tendo como corolário a dupla realização de preceitos indispensáveis, isto é, sempre quando os direitos fundamentais são respeitados, há também, simultaneamente, a concretização da dignidade humana, garantida a todos como fundamento do Estado Democrático de Direito.

Esse princípio também serve como critério e fundamento axiológico de qualquer interpretação e integração de normas dos ordenamentos jurídicos nacionais, possuindo absoluta preferência em qualquer conflito normativo, sendo ele uma espécie de "lei geral" para os direitos fundamentais, que são derivações da dignidade da pessoa humana (Sarlet, 1998, p. 115).

A dimensão e importância do princípio da dignidade humana nos ordenamentos jurídicos nacionais lograram grande influência, principalmente após a Declaração Universal dos Direitos do Homem de 1948, na qual consagrou-se diversos adágios essenciais para um direito humanista, 
como: o reconhecimento da dignidade humana como inerente a todos os membros da família humana, sendo todos os direitos, derivados desse princípio, iguais e inalienáveis firmando o fundamento da liberdade, da justiça e da paz no mundo; "todos os homens nascem livres e iguais em dignidade e direitos”. Além disso, assegura o direito de todos exigirem legitimamente a satisfação dos direitos econômicos, sociais e culturais indispensáveis, para que, assim, tenha-se uma ordem capaz de tornar plenamente efetivos os direitos e as liberdades enunciadas na Declaração, ou seja, assegurava-se o direito ao acesso à justiça para que as pessoas pudessem requerer a efetivação dos seus direitos em suas respectivas nações.

Com efeito, a passagem do dever-ser normativo constitucional para a realidade, mostra-se essencial para a efetivação dos direitos fundamentais, seja ela espontânea ou coercitiva, apenas sendo relevante, sob a ótica jurídica, que seja conforme a vontade geral e abstrata do legislador (Bedaque, 2009, p. 20), tendo em vista que tão somente a sua positivação em assento constitucional não possui utilidade se a sua efetividade não é pautada pelo Estado.

Assim, nota-se que a Constituição e o Direito, como um todo, devem buscar sua efetividade no cotidiano do cidadão, isto é, deve ocorrer a concretização de sua função social das normas constitucionais (Barroso, 1996, p. 79), ou melhor, a materialização, no mundo dos fatos, dos preceitos legais (Barroso, 2010, p. 221). Dessa forma, o Direito existe para se tornar realidade. A verificação se isto está realmente ocorrendo não pode ser estranha ao seu objeto de interesse e de estudo, isto é, a doutrina não pode relegar para um segundo plano a eficácia jurídica das normas em estudo (p. 217). Afinal, conforme assevera Sergio Cavalieri Filho, "pior do que não ter leis, é tê-las e não aplicá-las” (Cavalieri Filho, 2000, p. 92). O trabalho dos juristas é resgatar e aproveitar ao máximo a efetividade potencial das normas de direito fundamental (Bonifácio, 2008, p. 122-123). 
Para tanto, o Estado, como importante promotor do desenvolvimento, deve projetar metas e ações efetivas por meio de políticas públicas com o intuito de efetivar os direitos fundamentais, tais como a criação e aperfeiçoamento de escolas, melhoria em equipamentos médicos, e melhor preparo de oficiais das polícias, para que, assim, ocorra a concretização de normas de acordo com a força normativa da constituição, conforme pontificava o jurista Konrad Hesse. As constituições não podem ficar no plano da utopia, enquanto a sua força normativa (efetivação) não é vista na realidade, havendo a insinceridade constitucional por parte dos constituintes das diversas nações em desenvolvimento.

O Estado, por sua vez, possui como justificativa mais utilizada a teoria da reserva do possível, cuja ideia central é que somente se pode exigir uma prestação do Estado se for observada a razoabilidade da ação, isto é, o Estado poderia deixar de efetivar determinados direitos fundamentais, tendo como fundamento sua limitação em face de suas condições socioeconômicas e estruturais. Em termos mais simplórios, o Estado não estaria efetivando os direitos porque não possui verbas para tanto. Por este prisma, Dirley Cunha Junior assevera que "nem a reserva do possível, nem a reserva de competência orçamentária do legislador podem ser invocados como óbices, no direito brasileiro, ao reconhecimento e à efetivação de direitos sociais originários a prestações” (2008, p. 716).

Posto isto, pode-se, neste momento, relacionar a concretização desses preceitos constitucionais com as novas concepções do desenvolvimento. ${ }^{1}$ Conforme pode-se notar, os direitos fundamentais e sua efetivação possuem uma relação estreita com o cotidiano do cidadão, uma vez que

${ }^{1}$ Cf. SILVA, L. M.; GUIMARAES, P. B. V. Desenvolvimento pós-social: o Direito e Desenvolvimento sob a perspectiva pós-positivista. Revista do Instituto do Direito Brasileiro, v. 3, p. 5313-5344, 2014. Nesse trabalho teoriza-se o desenvolvimento pós-social que seria a visão do desenvolvimento como concretização e efetivação dos direitos e garantias fundamentais de acordo com a realidade e o contexto local, com o fito de garantir a todos uma vida digna. 
tais normas são pilares da estrutura básica da sociedade. Afinal, um país com uma educação boa, médicos dispostos e equipamentos adequados, policiais preparados que, efetivamente, proporcionem segurança, no qual seus cidadãos votem de forma livre, direta, secreta, periódica e, o atributo mais importante, universal, são pressupostos básicos de qualquer nação que esteja na trajetória do novo desenvolvimento. É fundamental a democracia nessa perspectiva efetivadora, posto que esse regime fornece o ambiente político mais poroso, de forma que favorece este processo dinâmico de transformação (Schapiro; Trubek, 2012).

Cabe, por fim, registrar a importância de tais efetivações para o processo dinâmico de emancipação social e, consequentemente, do desenvolvimento da nação. A moldura (ou alicerce), formada pelos pressupostos supraexpostos, são fundamentais na promoção da colaboração público-privada. Para que haja abertura de empresas, expansão de negócios, aumento de investimentos nacionais e internacionais, e tantos outros elementos básicos para o crescimento econômico, deve-se focar na qualificação do potencial humano, na expansão da infraestrutura, na desburocratização e na transparência, senão os empreendedores e as multinacionais irão focar seus investimentos em outras nações que, por sua vez, fornecem esses elementos basilares para suas atividades.

\section{A COLABORAÇÃO PÚBLICO-PRIVADA COMO INSTRUMENTO DO DESENVOLVIMENTO}

Quando se fala em colaboração público-privada torna-se necessário, já de início, deixar claro que não se limita apenas às situações que o Estado, por meio de contrato administrativo de concessão, atribui ao ator privado o dever de executar obra pública e (ou) prestar serviço público com auxílio do Poder Público, sendo o seu núcleo ainda maior, abarcando todo tipo de sinergia entre os setores público e privado, que viabilize o fim precípuo de todo o dinamismo do desenvolvimento, o interesse público, 
abrangendo a dignidade humana e o bem-estar dos cidadãos. Assim, as funções públicas e privadas cada vez mais se interpenetram e consubstanciam-se com a mesma finalidade.

Desde o momento neoliberal, os Estados reconheceram que não eram capazes de fazer os investimentos necessários em infraestrutura e nos projetos de cunho social (transporte, educação, saúde), seja porque não possuíam recursos suficientes, seja porque não tinham o know how suficiente para obter êxito em tais programas (Kurachi, 2007, p. 132).

Dessa forma, o Estado, visando a melhorar a qualidade de serviços públicos e, consequentemente, a efetivação dos direitos fundamentais, introduz diversos mecanismos que induzem uma maior participação da iniciativa privada nessa esfera pública que não ocorreriam caso a Administração Pública não tivesse provido tais incentivos para esses comportamentos econômicos e sociais. Isso ocorreu devido à mudança da percepção estatal, exsurgida nessas últimas décadas, notando sua morosidade inerente, encontrando como meio de lograr a eficiência e satisfação das necessidades do interesse coletivo, a abertura de competência das prestações ao setor privado (Ariño Ortiz, 2003, p. 330).

Diante do exposto, nota-se a mudança da função estatal, deixando de ser aquela administrativa-burocrática, hierárquica, unitária, para lograr a função de Estado fomentador-regulador-financiador-indutor. Ou seja, o Estado, tendo em vista sua burocracia, morosidade, ineficiência, corrupção e sua tendência patrimonialista, na qual "os titulares do poder se apoderam do aparelhamento estatal de tal forma que acaba por gerar uma quase indistinção entre o que é bem público (Estado) e o que é o bem privado" (Streck, 2011, p. 29), atribui aos sujeitos privados e à sociedade civil (terceiro setor) a prestação de determinados serviços públicos, enquanto adquire outra nova função, isto é, de fiscalizar, regular e induzir os atores 
privados no sentido do interesse público, perdendo seu monopólio no processo de realização direta das ações tendentes à satisfação das necessidades públicas.

Nesse sentido, conforme referido anteriormente, emerge-se o conceito de Estado regulador. Essa regulação estatal tem como objetivo, segundo Marçal Justen Filho "conjugar as vantagens provenientes da capacidade empresarial com a realização de fins de interesse público”. Para o mencionado autor, "especialmente quando a atividade apresentar relevância coletiva, o Estado determinará os fins a atingir, mesmo quando seja resguardada a autonomia privada no tocante à seleção dos meios” (2002, p. 30).

Partindo desse enfoque, Vital Moreira confere essa nova função de regulação estatal devido a diversos fatores, principalmente: “(i) redução do papel econômico do Estado, (ii) privatização de empresas públicas, (iii) diminuição dos poderes regulatórios, (iv) liberalização dos setores anteriormente sujeitos a regime exclusivo público ou privado, (v) limitação ou eliminação de serviços públicos e (vi) o fomento da concorrência nacional e internacional”. Isso ocorreria em virtude da importância regulatória dos mercados e nas sociedades do mundo, posto que é necessário (i) regular o mercado para garantir a concorrência; (ii) regular o mercado em razão de seus limites e falhas eventuais, para que o mesmo possa então funcionar; (iii) regular para afastar ou atenuar as externalidades negativas do funcionamento da economia (por exemplo, custos sociais associados a danos ambientais); (iv) regular para promover a proteção dos consumidores, e (v) regular para garantir as denominadas obrigações de serviço público" (Moreira, 2001, p. 223-247 apud Oliveira, 2005, p. 4; Justen Filho, 2002, p. 28-30).

Outras novas funções do Estado concebidas no paradigma contemporâneo do D\&D são as funções fomentadoras e financiadoras. Nesse aspecto, o Estado, ao invés de agir coercivamente - impondo ou proibindo 
condutas -, escolhe induzir, orientar, negociar, estimular, mediante sanções premiais, e inspirar os cidadãos e os grupos sociais a adotar comportamentos que ele possui como fim em suas atuações, por intermédio $d a$ soft law. Assim, conforme aponta Gaspar Ariño Ortiz, por meio de diversos estímulos, como, por exemplo, subvenções, isenções fiscais e créditos, o Estado não exige coercitivamente, isto é, não impõe (Ariño Ortiz, 2003, p. 340); pelo contrário, apenas faculta, ou melhor, favorece a colaboração dos particulares para que a atividade que está sendo fomentada seja realmente efetivada e oferecida com boa qualidade (Ariño Ortiz, 2003, p. 339).

Por isso, colaboração público-privada é assujeitada a um "controle intenso e contínuo, com a finalidade de conduzir os particulares a atingir resultados necessários ao bem comum” (Justen Filho, 2002, p. 28-30), possuindo os ordenamentos jurídicos diversos mecanismos e materiais de acompanhamento da atividade privada.

Essa colaboração público-privada segue os elementos preconizados pelo "novo Estado desenvolvimentista” (New Developmental State), elaborado por Trubek, como:

i) primary reliance on the private sector as investor rather than direct state ownership; ii) acceptance of a major role for the state in steering investment, coordinating projects and providing information especially in projects with multiple inputs and long term payoff; iii) extensive collaboration and communication between public and private sectors; iv) Strong interest in exports and relative openness to imports; v) direct attention to entrepreneurship, innovation, and new product development rather than reliance on imported technology and know-how; vi) promotion of productive (rather than speculative) foreign direct investments (FDI); vii) emphasis on making private firms competitive rather than on shielding them from competition; viii) privatization or public/ private partnerships in provision of public services; ix) promotion of domestic capital markets and the financial sector both to generate and 
to allocate resources; $\mathrm{x}$ ) attention to social protection including efforts to reduce inequality, maintain solidarity and protect against some of the costs of restructuring (2008, p. 11).

Além disso, a adoção desses elementos implica novas políticas públicas e instituições, como:

i) organized systems for public-private information sharing; ii) subsidized systems that will promote searches for promising products and market; iii) cooperative public-private efforts to construct regulatory regimes that foster global competitiveness and domestic efficiency; iv) efforts to create globally competitive national champions; v) major investments in education, $\mathrm{R} \& \mathrm{D}$, and technological innovation; vi) highly selective use of tariffs, taxes and subsidies to jump-start industries; vii) public venture capital-investment of public funds in promising companies; viii) use of public-private partnerships for major investments in infrastructure; ix) new mechanisms for solidarity such as basic income grants (Trubek, 2008, p. 12).

Outro aspecto importante dessa colaboração público-privada é o risk-sharing, que possui como cerne o compartilhamento de riscos entre esses dois entes (administração Pública e iniciativa privada) e a possibilidade de investimentos em áreas e setores que as restrições orçamentárias do Estado não permitem esse agente alcançar. Nesse sentido, cada ente deve gerir o risco que possui maior competência para controlá-lo e mitigá-lo. Ou seja, o setor privado deve(ria) assumir os riscos de construção e operacionais, enquanto o governo deve(ria) se concentrar nos riscos de políticas, fiscalização, fomento e regulação do projeto.

Ao estabelecer essa colaboração privada, com o escopo de oferecer um serviço de qualidade para a sociedade, deve haver um equilíbrio entre o risco assumido pelo Estado e os interesses privados. Afinal, o risco assumido pelo Estado é o risco assumido pela própria sociedade. Assim, não é razoável para o Estado, assumir um risco alto por uma obra ou serviço que tenha pouco retorno para a sociedade e para o desenvolvimento, 
sendo essencial a proporcionalidade entre o risco assumido e os benefícios que a colaboração público-privada proporcionará para o bem-estar da sociedade. Além disso, não se pode olvidar que se deve proporcionar condições para que as melhores empresas do ramo possam entrar nesse contrato público-privado, isto é, por meio de um compartilhamento de riscos e incentivos para as empresas, além dos valores envolvidos na negociação que proporcionem o equili $\square$ brio econômico-financeiro do empreendimento (Akitoby, Hemming; Schwartz, 2006, p. 11, Trubek, 2008, p. 30).

Em busca deste desiderato, os ordenamentos jurídicos devem imprimir uma nova compreensão do arcabouço legal, além de auxiliar na criação de novas normas e projetos que facilitem a aplicação desse tipo de colaboração. Tal compreensão deve ter como pressupostos a premiação e identificação do empreendedorismo e inovação; promover a boa governança, ou melhor, a maior transparência para tornar as nações melhores alvos de investimentos; reconhecer que a flexibilidade e segurança jurídica são importantes para essa colaboração público-privada, sendo necessária a harmonização desses elementos (Trubek, 2008, p. 19). Além disso, não se pode esquecer a importância da tutela da pessoa humana nesse processo, posto que o potencial humano é um elemento essencial no conjunto de fatores produção (Crozier, 1989, p. 99-101), sendo mister para aumentar a produtividade dos trabalhadores e, consequentemente, dos mercados e das nações.

\section{A RELEVÂCIA DO PLURALISMO JURÍDICO PARA A EFICÁCIA DAS NORMAS JURÍDICAS}

Outra questão central para a compreensão dos novos rumos do Direito e Desenvolvimento é aquela atinente à importância que o pluralismo jurídico possui para a eficácia de normas jurídicas e a sua relevância no processo de expansão jurisdicional. 
O pluralismo jurídico pode ser sintetizado como a coexistência de ordenamentos vigentes na mesma sociedade, e mostra-se fundamental na eficácia do Direito, dado que os ordenamentos paralelos conseguem abranger locais onde o ordenamento jurídico formal, tradicionalmente, não alcança. Com efeito, há décadas, juristas, sociólogos e economistas, de diversos países do mundo, perseguem incessantemente soluções para os sistemas legais ineficazes e inefetivos que passam por esse desafio. Já apontou-se para o rule of law que, por sua vez, não teve os resultados esperados.

Nesse sentido, os novos estudos e rumos do D\&D dirigem-se para o pluralismo jurídico como um dos recursos que podem solucionar o problema da ineficácia de normas jurídicas (Tamanaha, 2011, p. 19). Nesse processo, contudo, esbarra-se em duas questões primordiais, sendo uma delas negativa e a outra positiva, conforme Brian Tamanaha assevera. As questões negativas são as atinentes à possibilidade e ao grau de importância e de repercussão da coexistência de múltiplos ordenamentos jurídicos que podem afetar o Império do Direito (rule of law), ou, à luz de uma visão constitucional, o princípio da legalidade. Enquanto as questões positivas referem-se à possibilidade de fontes alternativas do direito, satisfazem funções que o ordenamento jurídico estatal e suas instituições não conseguem exercer com eficácia (Tamanaha, 2011, p. 1)

Nesse contexto, cumpre ressaltar que estabelecer que o Estado é a única fonte formal de regras de controle social, não quer dizer que ele deve ser a única e principal fonte de regras sociais. Cada sociedade possui diversas regras sociais provenientes de fontes diversas, como, por exemplo, hábitos, normas religiosas, regras morais, etiquetas sociais, normas de negócios. Alguns temas e locais onde tais regras estão sendo aplicadas possuem uma maior necessidade da intervenção do Estado, tal como ocorre nos casos de normas comerciais e normas imobiliárias. Em outras 
questões, como acontece com os costumes religiosos, o Estado se abstém na maioria dos casos, em virtude dos direitos individuais constitucionais de cada cidadão (Tamanaha, 2011, p. 6-7).

A problemática cinge-se no fato de que essas regras sociais e o nível de intervenção estatal na sociedade varia de Estado para Estado, de sociedade para sociedade. Por exemplo, no Brasil, em razão do passado histórico (ditadura militar), a comunidade jurídica e a própria sociedade colocam monta nos direitos individuais, como a liberdade de crença e a igualdade de direitos (Luna e Santos, 2014). Na Índia esses direitos, frequentemente, sofrem influência das normas do hinduísmo, pela vinculação estreita entre o direito indiano e a religião hinduísta. Enquanto um estupro de uma menor de idade, na Índia, não é recebido com tanta surpresa por causa da grande população conservadora-religiosa dessa nação, no Brasil diversos movimentos sociais e a própria população revoltam-se, exigindo a investigação desses casos.

É evidente que não existe uma solução única para a intervenção estatal nas regras sociais, nem mesmo o preconizado rule of law do segundo momento do D\&D (fase neoliberal) consegue criar um projeto único para todas as nações. Essa intervenção do Estado varia de acordo com as particularidades (cultura, sociedade, momento histórico, níveis de educação etc.) de cada nação e, principalmente, com as particularidades de cada sociedade. Assim, mostra-se necessário a adequação ao contexto e à realidade local de aplicação das normas.

Esse problema não é visto apenas no nível macro (de nação para nação), mas também no nível micro (de região para região), dentro de cada país, como uma unidade em si, ou até mesmo dentro da mesma cidade. À medida que nas comunidades mais pobres diversas instituições e regras formais do Estado não conseguem possuir seu efeito desejado, 
abre-se azo para que as regras e costumes (não formais) da comunidade tornem-se instrumentos mais fáceis para os indivíduos que vivem nesse contexto.

Essas regras, processos e costumes não estatais são, frequentemente, aceitos pela comunidade em consequência da proximidade, acessibilidade e adjacência das instituições não formais com o pensamento de grande parcela dos indivíduos que fazem parte dela. Além disso, esses processos são mais rápidos, mais baratos e mais amigáveis do que o processo formal do Estado, possuindo suas decisões maior eficácia do que o Direito formal (Tamanaha, 2011, p. 9).

Nesse contexto é notável a importância do pluralismo jurídico para que essas comunidades não se distanciem do Direito e de suas instituições e, como consequência, dos efeitos do processos desenvolvimento. Com efeito, as questões positivas ganham monta no sentido de aumentar o alcance das regras jurídicas.

Os ordenamentos jurídicos, em geral, nessa últimas décadas, vêm absorvendo as regras não estatais, retornando à posição de preponderância (monopólio) de outrora e também legitimando algumas instituições privadas de solução de problemas, como dando eficácia às decisões de arbitragens entre duas empresas (Tamanaha, 2011, p. 16). Ou seja, na perspectiva estatal, não importa com quais instrumentos a pacificação social e resolução de conflitos - finalidade de qualquer ordenamento jurídico - é alcançada, contanto, que os mecanismos utilizados não sejam incompatíveis com o ordenamento jurídico.

Além disso, à luz da perspectiva constitucional, não se pode olvidar da importância do acesso à Justiça e da pluralidade democrática nesse tema do pluralismo jurídico. $\mathrm{O}$ acesso à Justiça, sob uma visão da sociologia jurídica, mostra-se primordial para a eficácia da finalidade dos ordenamentos jurídicos e Constituições atuais, a qual se fundamenta, conforme exposto anteriormente, na pacificação social, resolução de conflitos e pro- 
moção do novo desenvolvimento (efetivação de direitos fundamentais). Trata-se do princípio exposto em grande parcela das Constituições contemporâneas, que se funda na ideia de que "a lei não excluirá da apreciação do Poder Judiciário lesão ou ameaça a direito”, chamado pela doutrina de princípio da inafastabilidade da jurisdição, direito de ação, princípio do livre-acesso ao Judiciário ou, segundo Pontes de Miranda, princípio da ubiquidade da Justiça (Miranda, 1939).

Por isso, mostra-se necessária a absorção de normas não estatais pelo ordenamento jurídico formal, na medida em que nos "tribunais paralelos”, mesmo podendo ser considerado justo para determinados indivíduos da comunidade, não se utilizam do devido processo legal e de suas inerentes consequências. Além disso, o Estado não possui controle nenhum sobre as decisões dos “juízes paralelos”. Por exemplo, se um juiz da comunidade, que não possui preparo jurídico, decide tendo como única fonte de hermenêutica a moral, sem qualquer fundamentação teórica ou legal, o Estado não poderá intervir, senão nos casos em que as partes buscam reivindicar seu direitos no Poder Judiciário.

É de se notar, então, que, nesses casos paralelos, a harmonização do Estado com esses ordenamentos jurídicos não formais ganha monta, posto que os tribunais da comunidade estão compreendendo casos que, frequentemente, não iriam parar no Judiciário, seja porque os cidadãos das comunidades perderam a confiança no Estado e no Judiciário, seja porque não possuem recursos para pagar os honorários do advogado, ou porque não querem esperar décadas para uma decisão. O Estado, ao invés de abolir esse pluralismo, deve procurar formas de formalizá-lo ou, pelo menos, buscar extrair ideias de tais experiências, buscando melhorar cada vez mais a apreciação do Judiciário.

No Brasil, por exemplo, foram criados os Juizados Especiais Cíveis, com o fito de acelerar os procedimentos de ações que envolvam até o valor de 40 salários mínimos (em torno de 30 mil reais). Nesses juizados, 
pauta-se pela objetividade e celeridade, sendo as suas ações completamente gratuitas, não mostrando necessária a presença de um advogado nas causas até 20 salários mínimos. Registra-se que tal solução foi criada pela falta de provocação ao Judiciário em causas de pequeno valor por parte dos cidadãos que julgavam que seria muito desgasto nas ações, sem possuir um retorno no seu investimento emocional, de tempo e dinheiro (honorário dos advogados). Frequentemente, tais pessoas procuravam formas paralelas de solução para seus problemas. Assim sendo, ao criar os Juizados Especiais Cíveis, não exigindo as mesmas formalidades da Justiça Comum, o Estado, além diminuir o número de demandas na Justiça Comum, acelerando os processos, também buscou albergar parte da população que se sentia excluída do Poder Judiciário, promovendo o pluralismo jurídico.

Igualmente, não se pode olvidar que a ideia de pluralidade está vinculada estreitamente ao conceito de democracia, podendo, até mesmo, ser considerada um de seus pilares. A democracia, por sua vez, conforme assevera o jurista alemão Peter Häberle, está interligada aos direitos humanos, sendo o pluralismo o ponto de referência das Constituições modernas. Assim sendo, a Constituição, para o mencionado autor, seria um processo em constante desenvolvimento, que representa a sociedade plural e aberta de onde foi criada, sendo ela um produto cultural desta. Nesse sentido, Häberle preconiza a democratização da interpretação constitucional, isto é, que os juristas não são os únicos intérpretes da Constituição, uma vez que todos os cidadãos que vivem em uma sociedade aberta (e pluralista) são legítimos intérpretes da Constituição (Häberle, 1997).

Partindo desse enfoque, há como consequência da hermenêutica constitucional aberta a relativização do estatismo em matéria de fontes do direito, ou melhor, a pluralidade de fontes do direito (Häberle, 2003, p. 128). Afinal, a ideia de que a única fonte do direito é o Estado, sugere que o Direito é algo acabado, dado de uma única fonte e, na práxis jurídica, não é isso que acontece. Com efeito, o Direito é uma ciência plural, não se cingindo seu discurso a que o Estado diz que é fonte do Direito ou uni- 
camente ao nível textual, mas também albergando os diversos elementos que contribuem para a hermenêutica do direito constitucional hodierno, conformando-a, de acordo com os diversos fenômenos e acontecimentos da realidade, com o escopo de promover a concretização constitucional. Ou seja, com a abertura do sistema jurídico promovida pela teoria haberliana, há uma abertura de espaço para exposições advindas de fontes do direito não estatais, sempre com o objetivo de promover as estratégias emancipadoras e concretizadadoras do Direito.

\section{A UTILIZAÇÃO DA PROPRIEDADE INTELECTUAL COMO INSTRUMENTO DE FOMENTO À INOVAÇÃO}

No processo de desenvolvimento, o aperfeiçoamento das normas e medidas referentes à proteção da propriedade intelectual dos inventores, investidores, estudantes e empresas, mostram-se essenciais para uma economia sólida, cujos ideais baseiam-se em ambiente profícuo para o desenvolvimento científico e uma mudança institucional e cultural, no sentido de engendrar condições e estímulos para que as empresas, universidades e institutos científicos e tecnológicos tenham possibilidade de criar produtos de ponta que influenciem o cotidiano do cidadão e dos diversos setores da indústria nacional. Entre esses estímulos, a propriedade intelectual é uma das mais relevantes, uma vez que suas diretrizes são responsáveis por proteger anos de pesquisa e experimentação dos inventores, fornecendo-os exclusividade por um período de tempo, por meio da patente, transformando suas ideias em bem privado.

Nesse contexto, encontra-se um dos maiores problemas da propriedade intelectual, que se fundamenta na dificuldade de promover a inovação - por meio do fornecimento da propriedade intelectual - e, concomitantemente, promover colaboração entre os diversos institutos da sociedade, isto é, incentivar a circulação das ideias, pressuposto necessário para o desenvolvimento científico e da sociedade. Afinal, a própria finalidade das medidas de propriedade intelectual, além de proteger o inventor, é a divul- 
gação de ideias e o acesso público sobre os pontos essenciais reivindicados pelo criador, que auxiliem diversos produtos e pesquisas na área de criação, inspirando outros inventores a criar produtos derivados ou mais bem relacionados a tal invento.

Não é objetivo deste artigo esgotar esse tema tão atual e complexo, mas, sim, trazer à luz os pressupostos necessários para que a propriedade intelectual auxilie a inovação e desenvolvimento, ao invés de criar óbices à criação de conhecimentos.

Nesse diapasão, faz-se evidente a necessidade da consolidação de um arcabouço legal, que permita dinamizar a relação entre universidades, institutos de pesquisa e o setor produtivo nacional (Matias-Pereira; Kruglianskas, 2005), promover o acesso às informações referentes à propriedade intelectual e à inovação nacional, acelerar o tempo de processamento de patentes por meio de fomentos e expansão dos institutos que viabilizam essa tarefa, alinhar os interesses das universidades e institutos tecnológicos com os interesses dos setor empresarial, para que, assim, possa se criar um conhecimento que seja útil para o mercado e para os cidadãos, bem como promover uma mudança cultural quanto aos incentivos à inovação. Tais pressupostos mostram-se necessários para promover a segurança jurídica, que tem como consequência mais investimentos, desenvolvimento econômico e, ainda, desenvolvimento do potencial humano (Monte-Silva; Dantas, 2013).

\section{A PROBLEMÁTICA DA CONTEXTUALIZAÇÃO DAS BASES TEÓRICAS AO LOCAL DE INSTITUIÇÃO DO PROCESSO DE DESENVOLVIMENTO}

A contextualização às necessidades e às particularidades da realidade e contexto local, na qual serão aplicadas as medidas de desenvolvimento, avulta importância nesse momento contemporâneo do D\&D. Assim, afasta-se e nega-se a fórmula única geral para todos os países - "one 
size fits all" -, preconizada pela teoria neoliberal do segundo momento, em prol de teorias e ideias que são formadas e construídas de acordo com as especificidades de cada economia e região, por meio de análises empíricas e históricas do contexto onde as ideias serão aplicadas (Trubek, 2008, p. 9).

Nesse sentido, pode ser trazida à baila a visão crítica de Brian Tamanaha, professor da Washington University, sobre a impossibilidade da aplicação de um solução única, in casu, rule of law, em vários países em desenvolvimento, sem qualquer tipo de adaptação ao contexto local. Afinal, conforme assinala o autor, cada sociedade possui uma história, cultura, recursos humanos, composições religiosas e étnicas, conhecimento, demografia, condições econômicas e a política díspares das outras, isto é, situam-se em contextos diferentes; por isso, não há possibilidade de existir uma fórmula padrão para a regulação de todas as sociedades sem que ocorra qualquer tipo de modificação. Por exemplo, uma lei que é considerada eficaz na Argentina pode ser disfuncional e ter consequências inesperadas em Taiwan (Tamanaha, 2010, p. 178).

Tal autor, esclarecendo essa questão, mostra a ineficácia do segundo momento do D\&D e, por extensão, do Império do Direito (rule of law), em razão da falta de contextualização de ideias. No sentido de fundamentar sua argumentação, traz à baila os escritos de Thomas Carothers, diretor do projeto rule of law e um dos seus maiores preconizadores na modernidade, nos quais afirma:

Os efeitos desse crescente apoio ao Império do direito são, em geral, positivos, embora comumente modestos. Depois de mais de dez anos e centenas de milhões de dólares de subsídio, muitos sistemas jurídicos na América Latina ainda funcionam mal. [...] Os mantenedores dos subsídios ajudaram a reescrever as leis em todo o mundo, mas descobriram que a mera promulgação de leis pouco alcança sem um investimento considerável na alteração das condições de implementação e execução [...] (Carothers, 2006).

Nesse contexto, Tamanaha alvitra que a questão da ineficácia, ou melhor, da eficácia modesta do rule of law, cinge-se à falta de coerência interna no momento de seleção dos candidatos à aplicação dos projetos do 
Império do Direito. As agências de desenvolvimento, como o Banco Mundial, a título de exemplo, utilizando um critério negativo de elegibilidade para tais projetos, cometem um erro, de tal sorte que países totalmente díspares, como a Argentina e o Egito, ou a China e El Salvador, cuja sociedade, recursos naturais, história, cultura, mistura de religiões e grupos étnicos, sistema político, grau de industrialização, produção agrícola, grau de urbanização, renda per capita, entre outros indicadores, são totalmente diferentes, com poucos denominadores comuns que justifiquem a aplicação do rule of law, e mesmo assim, são aplicadas as diretrizes do Império do Direito sem contextualizações. Para o mencionado autor, as agências de desenvolvimento não podem tão somente procurar "qualquer país que não tenha sido admitido no clube do capitalismo avançado" e adotar os ideais preconizados pelo segundo momento do $\mathrm{D} \& \mathrm{D}$, porquanto não terá os efeitos e o desenvolvimento desejado (Tamanaha, 2010, p. 180).

Com efeito, como pode-se notar pelo caminho percorrido até o momento, não há um percurso certo para o desenvolvimento sem que haja qualquer tipo de óbice ou de adaptações necessárias. Há, tão somente, determinados pressupostos, ideais e fundamentos que se mostram primordiais para o desenvolvimento contemporâneo, mas, nunca, uma solução única. Entre tais pressupostos e ideais pode-se arrolar a necessidade de um Estado transparente e aberto, cujas bases tenham como fundamento a boa governança, colaboração de ideais, colaboração público-privada e os fundamentos do pós-positivismo - efetivação dos direitos fundamentais e primazia da dignidade humana -, além de ter como eixo os pilares do Estado Democrático de Direito (Trubek, 2008, p. 10).

\section{CONCLUSÃO}

À guisa de conclusão, vislumbra-se a proficuidade dos novos rumos do Direito e Desenvolvimento, possuidores de caráter indisciplinar, abrangendo os mais diversos campos do Direito, como Direito Constitucional, 
Direito Administrativo, Direito Autoral, Direito Econômico, Direito Financeiro, bem como, indiretamente, outras ciências afins, tal como a Estatística, a Ciência Política e a Sociologia.

Além disso, observa-se a importância do "dever ser" normativo, consagrado em sede constitucional, para a efetivação dos direitos fundamentais, seja ela espontânea ou coercitiva, apenas sendo relevante, sob a ótica jurídica, que seja conforme a vontade geral e abstrata do legislador, uma vez que, tão somente a sua positivação em assento constitucional, não possui utilidade se a sua efetividade não é pautada pelo Estado.

Para tanto, o Estado deve promover uma abertura para a sociedade, trazendo para si a responsabilidade de mecanismos e áreas que não conseguem efetividade suficiente sem ação estatal, ou que conseguem efetividade, mas não com a segurança juridicial fornecida pelo Estado (pluralismo jurídico). Por outro lado, o ente estatal deve induzir uma maior participação da iniciativa privada na esfera pública em que o Estado mostra-se burocrático e letárgico aos anseios da sociedade, deixando assim, que os entes privados melhorem a qualidade do serviço "público”. As funções do Estado sofrem tranformações, suas atividades deixam de ser aquelas administrativa-burocráticas, hierárquicas, unitárias, para lograr a nova função de Estado fomentador-regulador-financiador-indutor. Nesta senda, faz-se mister que os ordenamentos jurídicos imprimam uma nova compreensão do arcabouço legal, além de auxiliar na criação de novas normas e projetos que facilitem a aplicação desse tipo de colaboração.

Sobreleva notar, por fim, que não há fórmula única geral para todos os países - "one size fits all" -, tornando-se essencial que as teorias e ideias se formem e sejam construídas de acordo com as especificidades de cada economia e região, por meio de análises empíricas e históricas do contexto onde as ideias serão aplicadas, ou seja, adotando uma contextualização às necessidades e particularidades da realidade e contexto local. 


\section{REFERÊNCIAS}

AKITOBY, B.; HEMMING, R.; SCHWARTZ, G. Public Investment and Public-Private Partnerships. Economic Issue n. 40. 2006.

ARIÑO ORTIZ, G. Principios de derecho público económico. Bogotá: Universidad Externado de Colombia, 2003.

BARROSO, L. R. Curso de Direito constitucional contemporâneo. São Paulo: Saraiva, 2009.

Curso de direito constitucional contemporâneo: os conceitos fundamentais e a construção do novo modelo. 2. ed. São Paulo: Saraiva, 2010. . Interpretação e aplicação da Constituição. São Paulo: Saraiva, 1996.

BEDAQUE, J. R. dos S. Direito e processo: influência do direito material sobre o processo. 5. ed. rev. e ampl. São Paulo: Malheiros, 2009.

BONIFÁCIO, A. C. O Direito constitucional internacional e a proteção dos Direitos fundamentais. 1. ed. São Paulo: Método, 2008. V. 8. (Coleção Professor Gilmar Mendes).

CAROTHERS, Thomas. The Rule of Law Revival. In: CAROTHERS, Thomas. Promoting the Rule of Law Abroad. Washington D.C.: Carnegie Endowment, 2006.

CAVALIERI FILHO, S. Programa de sociologia jurídica. 8. ed. Rio de Janeiro: Forense, 2000.

CROZIER, M. Estado modesto, estado moderno: estratégia para uma outra mudança. Brasília: Funcep, 1989. p. 99-101.

CUNHA JÚNIOR, D. Curso de direito constitucional. Salvador: Juspodivm, 2008.

HÄBERLE, P. As dimensões da dignidade da pessoa humana: construindo uma compreensão jurídico-constitucional necessária e possível. In: SARLET, Ingo Wolfgang (Org.). Dimensões da dignidade: ensaios de filosofia do Direito e Direito constitucional. Porto Alegre: Livraria do Advogado, 2005. p. 15-43. 
. El estado constitucional. Trad. Hector Fix-Fierro. México: Universidad Nacional Autônoma de México, 2003.

. Hermenêutica Constitucional: a sociedade aberta dos intérpretes da Constituição: contribuição para a interpretação pluralista a procedimental da Constituição. (Trad.). Gilmar Ferreira Mendes. Porto Alegre: Sergio Antonio Fabris, 1997.

KURACHI, N. K. A parceria público-privada como instrumento efetivo do desenvolvimento econômico e social. Dissertação (Mestrado em Direito) - Unimar, Marilia, 2007.

JUSTEN FILHO, M. O direito das agências reguladoras independentes. São Paulo: Dialética, 2002.

LUNA, Nevita Maria Pessoa de Aquino Franca; SANTOS, Gustavo Ferreira. Liberdade de expressão e discurso do ódio no Brasil. Revista Direito e Liberdade, Natal, v. 16, n. 3, p. 227-255, set./dez. 2014. Quadrimestral.

MATIAS-PEREIRA, J.; KRUGLIANSKAS, I. Gestão de inovação: a lei de inovação tecnológica como ferramenta de apoio às políticas industrial e tecnológica do Brasil. RAE Eletrônica, São Paulo, v. 4, n. 2, p. 1-21, 2005. Disponível em: $<\mathrm{http}$ ://repositorio.unb.br/bitstream/10482/917/1/ARTIGO_GestaoInovacao.pdf . Acesso em: 25 dez. 2013.

MIRANDA, Pontes de. Comentários à Constituição Federal de 1937. Rio de Janeiro: Irmãos Pongetti Editores, 1939. Tomo I.

MONTE-SILVA, Lucas do; DANTAS, Thomas Kefas de Souza. Incentivos públicos à Inovação: Análises, Críticas e Proposições. GEINTEC-Gestão, Inovação e Tecnologias, v. 3, n. 3, p. 221-234, 2013.

OLIVEIRA, G. H. J. Parceria público-privada e Direito ao desenvolvimento: uma abordagem necessária. Revista Eletrônica de Direito Administrativo Econômico, Salvador, Instituto de Direito Público da Bahia, n. 3, ago./set./out. 2005. Disponível em: <http://www.direitodoestado.com.br >. Acesso em: 26 dez. 2013

SARLET, I. W. A eficácia dos direitos fundamentais. Porto Alegre: Livraria do Advogado, 1998. 
QUERINO, Ana Célia; SILVA, Juvêncio Borges. Diversidade cultural: proteção e tutela na pós-modernidade. Revista Direito e Liberdade, Natal, v. 16, n. 3, p. 11-35, set./dez. 2014. Quadrimestral.

SCHAPIRO, M. G.; TRUBEK, D. M. Redescobrindo o direito e desenvolvimento: experimentalismo, pragmatismo democrático e diálogo horizontal. In: SCHAPIRO, Mario G.; TRUBEK, David M. (Orgs.). Direito e desenvolvimento: um diálogo entre os Brics. São Paulo: Saraiva, 2012.

SILVA, L. M.; GUIMARAES, P. B. V. Desenvolvimento pós-social: o direito e desenvolvimento sob a perspectiva pós-positivista. Revista do Instituto do Direito Brasileiro, v. 3, p. 5313-5344, 2014.

STRECK, L. L. Hermenêutica jurídica e $(m)$ crise. 10. ed. Porto Alegre: Livraria do Advogado, 2011.

TAMANAHA, B. Z. The rule of law and legal pluralism in development. Washington University in St. Louis Legal Studies, 2011. (Research Paper, n. 11-0701). Disponível em: <http://papers.ssrn. com/sol3/papers.cfm?abstract_ id=1886572>. Acesso em: 19 dez. 2013.

. O primado da sociedade e as falhas do direito e desenvolvimento. In: Revista Direito GV, São Paulo, 6. ed., p. 175-212, 2010.

TRUBEK, D. M. Developmental States and the Legal Order: Towards a New Political Economy of Development and Law. 2008. Disponível em: $<\mathrm{http}: / /$ papers.ssrn.com/sol3/papers.cfm?abstract_id=1349163>. Acesso em: $20 \mathrm{dez}$. 2013.

Recebido em: 25/12/2014

Aceito em: 25/4/2015 